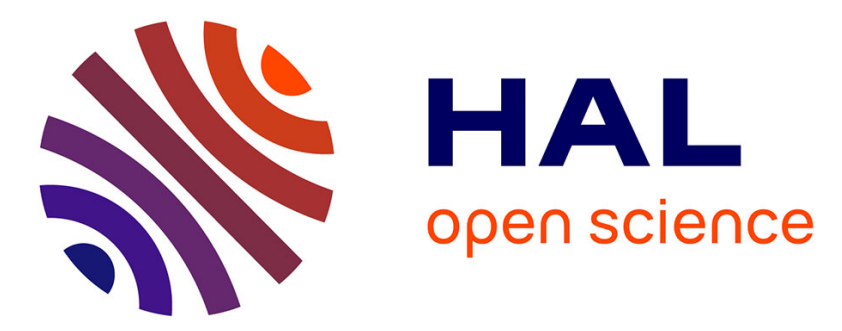

\title{
Emergency vaginal cervico-isthmic cerclage
}

Claire Szmulewicz, Marie-Emmanuelle Neveu, Solène Vigoureux, Hervé

Fernandez, Perrine Capmas

\section{To cite this version:}

Claire Szmulewicz, Marie-Emmanuelle Neveu, Solène Vigoureux, Hervé Fernandez, Perrine Capmas. Emergency vaginal cervico-isthmic cerclage. Journal of Gynecology Obstetrics and Human Reproduction, 2019, 48, pp.391 - 394. 10.1016/j.jogoh.2019.03.023 . hal-03484611

\section{HAL Id: hal-03484611 \\ https://hal.science/hal-03484611}

Submitted on 20 Dec 2021

HAL is a multi-disciplinary open access archive for the deposit and dissemination of scientific research documents, whether they are published or not. The documents may come from teaching and research institutions in France or abroad, or from public or private research centers.
L'archive ouverte pluridisciplinaire HAL, est destinée au dépôt et à la diffusion de documents scientifiques de niveau recherche, publiés ou non, émanant des établissements d'enseignement et de recherche français ou étrangers, des laboratoires publics ou privés.

\section{(ㄷ)(1) $\$$}

Distributed under a Creative Commons Attribution - NonCommerciall 4.0 International 


\title{
Emergency vaginal cervico-isthmic cerclage
}

SZMULEWICZ Claire ${ }^{1}$, NEVEU Marie-Emmanuelle ${ }^{1,2}$, VIGOUREUX Solène ${ }^{1,2,3}$, FERNANDEZ Hervé ${ }^{1,2,3}$, CAPMAS Perrine ${ }^{1,2,3}$.

${ }^{1}$ AP-HP, Hôpital Bicêtre, GHU Sud, Department of Gynecology and Obstetrics, 94276 Le Kremlin-Bicêtre, France

${ }^{2}$ Inserm, Centre of Research in Epidemiology and Population Health (CESP), U1018, 94276 Le Kremlin-Bicêtre, France

${ }^{3}$ University Paris Sud Orsay, 94276 Le Kremlin-Bicêtre, France

\author{
CORRESPONDING AUTHOR: \\ Perrine CAPMAS \\ Department of Gynecology and Obstetrics, \\ Hôpital Bicêtre, \\ GHU Sud, AP-HP, \\ 78 avenue du General Leclerc \\ 94276 Le Kremlin-Bicêtre, France \\ $+331452117714$ \\ perrine.capmas@aphp.fr
}

\section{CONFLICTS OF INTEREST: No}

The authors declare that they have no known competing financial interests or personal relationships that could have appeared to influence the work reported in this paper.

FUNDING: No 


\section{Abstract}

Objective: Cervical cerclage is the principal treatment for women with a cervical insufficiency, which is a predominant factor in second trimester loss and preterm birth. A cervico-isthmic cerclage is recommended in case of a previous failure of McDonald cerclage or in case of an absent portio vaginalis of the cervix. In women who have prolapsed membranes at or beyond a dilated external cervical os before 24 weeks of gestation, an emergency cerclage can sometimes be performed. The aim of this study is to report our experience with emergency transvaginal cervico-isthmic cerclage.

Study Design: This is a retrospective, single-centre study conducted between 2009 and 2017 of women who received a transvaginal cervico-isthmic emergency cerclage. Emergency cerclage was defined as cerclage performed on women who had prolapsed membranes at or beyong a dilated external cervical os before 24 weeks of gestation. The exclusion criteria were twin pregnancy, preterm rupture of membranes, and clinical or biological signs of infection.

Results: Three women were included. One woman had a history of failure of emergency McDonald cerclage during her previous pregnancy. The two other women had a failure of McDonald cerclage during index pregnancy. All women presented prolapsed membranes at or beyond a dilated external cervical os as defined for an emergency cerclage. The emergency cerclage was performed at a mean gestational age of 21.5 weeks of gestation. The average gestational age of delivery was 38.5 weeks of gestation by caesarean section.

Conclusion: Despite the small number of women, this study shows that this type of cerclage was effective in pregnancy prolongation for women at high risk of preterm birth in case of McDonald cerclage failure. Nevertheless, this technique requires a trained surgical team. A randomised trial should be performed to evaluate the need for emergency vaginal cervicoisthmic cerclage. 
Keywords: cervico-isthmic cerclage; emergency cerclage; cervical insufficiency; late fetal loss; premature delivery 


\section{INTRODUCTION}

Spontaneous preterm deliveries are a major cause of perinatal morbidity and mortality and have lifelong effects on child development. The preterm birth rate is currently increasing in some middle- and high-income countries. In 2016, the rate was $7.5 \%$ in France and $9.5 \%$ in the United States (1) (2).

A predominant factor in second trimester loss and preterm birth is cervical incompetence, which is estimated to complicate $0.5-1 \%$ of all pregnancies. However, there is no consensus on its definition. The most common is the incapacity of the uterus cervix to maintain a pregnancy without symptoms such as uterine contractions before 37 weeks (3). The diagnosis of cervical incompetence is evocated after a history of second-trimester loss without associated uterine contractions. No diagnostic test has demonstrated a capacity to confirm cervical incompetence (4).

Cervical cerclage is the principal treatment for women with a history of cervical insufficiency.

Three types of cerclage can be differentiated: prophylactic, therapeutic and emergency. According to French recommendations, prophylactic cerclage is practiced at the end of the first trimester for patients who have had 3 occurrences of preterm birth or late fetal loss. Therapeutic cerclage is for women who had 1 occurrence of preterm birth associated with cervical modifications (cervical length $<25 \mathrm{~mm}$ during transvaginal ultrasonographic follow-up).

Emergency cerclage is practiced during the second trimester for women who have prolapsed membranes at or beyond a dilated external cervical os before 24 weeks of gestation. Only one randomised controlled trial evaluates emergency cerclage efficiency (5). Althuisius et al. conclude that emergency cerclage reduces the risk of preterm delivery before 34 weeks of gestation and neonatal morbidity compared with bed rest or indomethacin alone. In this study, emergency cerclage was practiced using the McDonald technique. Many other retrospective studies show that emergency cerclage prolonged the duration of pregnancy compared with expectant management without an increase in maternal morbidity (6-9). 
Several cerclage techniques have been developed since the 1950s.

The first is the Shirodkar cerclage, which consists in the dissection of the vesico-cervical mucosa and placement of a suture (human fascia lata in the original description) as close to the internal cervical os as possible (10). Later, McDonald described a technique in which a simple purse-string suture of non-resorbable material was inserted at the cervicovaginal junction without bladder dissection (11). These two are the most commonly practiced techniques.

In 1965, Benson and Durfee described a cervico-isthmic cerclage before pregnancy by laparotomy (12). Later, laparoscopic and vaginal approaches were developed to reduce the morbidity of abdominal techniques $(13,14)$. Finally, Fernandez et al. described in 2006 a cervico-isthmic cerclage with placement of a polypropylene sling by vaginal approach (15). This technique is realised during the first trimester of pregnancy. It shows satisfactory results for an ongoing pregnancy with a median gestational age at birth of 37.2 weeks and an overall neonatal survival rate of $94 \%$. This cerclage is recommended in case of a history of failure of McDonald cerclage in a previous pregnancy or in case of an absent portio vaginalis of the cervix (15) .

For selected patients and in the hands of experimented surgeons, emergency cerclage using Fernandez's technique can be used.

The aim of this study is to report our experience with definitive emergency transvaginal cervicoisthmic cerclage. 


\section{MATERIALS AND METHODS}

This retrospective study was conducted between January 2009 and December 2017 in a French referral teaching hospital. The study received IRB approval number CEROG 2016GYN-0302.

The inclusion criteria were women with a single pregnancy who received an emergency cervico-isthmic cerclage because of major cervical modifications (cervix length lower than $25 \mathrm{~mm}$ by transvaginal echography) with or without prolapsed membranes between 15 and 24 weeks of gestation.

Indications of programmed vaginal cervico-isthmic cerclage with Fernandez's technique were two occurrences of late miscarriage, including one despite McDonald cerclage.

The indications of emergency cervico-isthmic cerclage were prolapsed membrane at or beyond the cervical os before 24 weeks of gestation with a previous McDonald cerclage failure or cervical modifications despite implementation of McDonald cerclage during the same pregnancy.

At admission, a gynaecological exam was performed using speculum in order to see cervical os and eliminate membrane rupture. A sonography was carried out to check fetal vitality and measure cervical length. Clinical or biological signs of infection (fever, tachycardia, uterine contraction, leukocytosis, elevated C-Reactive protein (CRP) or positive vaginal swab) were notified.

Exclusion criteria were twin pregnancy, preterm rupture of membranes, and clinical or biological signs of infection (chorioamniotis).

The data gathered included: age, BMI, parity, uterine abnormalities, history of cone biopsy, history of cerclage from previous pregnancies, gestational age at moment of cerclage, cervical status, pregnancy and neonatal outcomes. Obstetric data was collected by consulting medical records. Then, emergency cerclage was performed. 
Surgical technique (15):

The procedure is performed under loco-regional (spinal) anaesthesia preferably during pregnancy or rarely under general anaesthesia, depending on the patient's wishes, comorbidities and the practice of anaesthetic teams. A prophylactic antibiotic treatment by cephalosporin is systematic during surgery. Surgery is performed as soon as possible after exclusion of a septic context.

The woman is placed in a modified lithotomy position with a steep Trendelebourg tilt. If necessary, the prolapsed membranes are gently pushed back into the uterine cavity. Paracervical infiltration with physiological saline and lidocaïne is performed. An anterior semicircular colpotomy at the cervico-vaginal junction is done. Then, the bladder is repulsed until exposition of the cervico-isthmic junction and reclined with the vaginal valve. Posterior colpotomy is performed to open the Douglas pouch. We insert a non-absorbable polypropylene sling around the cervico-isthmic junction above the uterosacral ligaments. After tightening, a tape is fixed to the anterior surface of the isthma with non-absorbable sutures and the colpotomies are closed using absorbable sutures.

After surgery, women usually receive a non-steroidal anti-inflammatory suppository for 48 hours, and have to rest. A vaginal swab is performed every month until the end of the pregnancy. As the cerclage is definitive, a caesarean section is planned around 38 weeks of gestation. 


\section{RESULTS}

During the study period, 143 vaginal cervico-isthmic cerclages were performed. Twenty-four of them were performed between 15 and 24 weeks of gestation. Twenty-one women received a prophylactic cervico-isthmic cerclage after 15 weeks of gestation because they were addressed later during pregnancy and three women were included in this study as they had an emergency cerclage.

\section{Case 1:}

The first case was a 30-year-old woman with no living child. She had a history of late miscarriage at 18 weeks of gestation but no history of conisation or uterine malformation. An emergency McDonald cerclage was performed at 17 weeks of gestation, but was removed four days later because of serious chorioamniotis.

For the next pregnancy, she did not have a prophylactic cerclage as recommended in the case of a single previous late miscarriage, and underwent cervical monitoring. At 19 weeks of gestation, major cervical modifications were diagnosed with prolapsed membranes beyond the cervical os. The cervical length was $20 \mathrm{~mm}$. She did not have any sign of infection or contraction. Blood sample results were normal without inflammatory syndrome (Leukocytes $7630 / \mathrm{mL}$ and negative CRP). A vaginal cervico-isthmic cerclage under spinal anaesthesia was performed at 19.5 weeks of gestation without complication. Operative length was 65 minutes. The woman delivered at 39 weeks by caesarean section.

\section{$\underline{\text { Case 2: }}$}

The second case was a 24-year-old woman with no living child. She did not have a conisation or a uterine malformation

She had a previous late miscarriage at 22 weeks of gestation, but she never had a cerclage. During this pregnancy, cervical modifications were diagnosed at 21 weeks of gestation leading to an emergency McDonald cerclage. At 23 weeks of gestation, at a follow-up consultation, 
membranes were beyond the cervical os and the cervical length was $15 \mathrm{~mm}$. She had no biological inflammatory syndrome (Leukocytes 11680 , CRP negative). A vaginal cervicoisthmic cerclage was performed without complications under spinal anaesthesia. Operative length was 60 minutes. The woman was admitted for a threatened preterm delivery at 26 weeks of gestation. She had corticosteroid treatment for fetal pulmonary maturation; finally, she delivered at 38.3 weeks of gestation by caesarean section.

\section{Case 3:}

The third case was a 22-year-old woman with two previous late miscarriages without cerclage. She did not have a previous conisation or a uterine malformation. She had not gone for a consultation during the first trimester of pregnancy and a prophylactic cerclage could not be performed. At 20 weeks of gestation, an emergency McDonald cerclage was performed for major cervical modifications. Despite this cerclage, membranes were beyond the cervical os and the cervical length was $4 \mathrm{~mm}$ at 22 weeks of gestation. Blood sample results were normal with leukocytes at 10,000 and negative CRP. A vaginal cervico-isthmic cerclage was performed under spinal anaesthesia. Surgical length was 65 minutes. The woman delivered at 38.2 weeks of gestation by caesarean section.

All women received a tocolysis with non-steroidal anti-inflammatory suppository (Indomethacine) during a 48-hour period. The three women did not experience any surgical complications or infections. 


\section{DISCUSSION}

This paper reports on 3 cases of definitive vaginal emergency cervico-isthmic cerclage among women who presented major cervical modifications after failure of McDonald cerclage during previous or current pregnancy. This cerclage was effective in pregnancy prolongation for these three women in spite of many poor prognostic factors. None of them had another pregnancy with this cerclage yet.

Cervico-isthmic cerclage has been demonstrated to be effective for women with a long history of previous second trimester loss and McDonald cerclage failure.

Some retrospective studies have concluded that in women with a prior failed McDonald cerclage, transabdominal cervico-isthmic cerclage is associated with a lower incidence of preterm delivery and preterm premature rupture of membranes in comparison with McDonald cerclage (16)(17).

Published studies about vaginal cervico-isthmic cerclage by Deffieux et al., Capmas et al. and Neveu et al. found a preterm birth rate of $19 \%$ (delivery before 37 weeks) with cervico-isthmic cerclage and an overall survival rate higher than $90 \%$ (15) (18). Capmas et al. compared McDonald cerclage and transvaginal cervico-isthmic cerclage in women with a prior failed McDonald prophylactic cerclage. They found no significant difference in the rate of delivery after 30 weeks of gestation, but the two groups were not comparable. Women in the cervicoisthmic cerclage group seemed to be at higher risk of premature delivery with older age, more prior late fetal loss and fewer live children (19).

In a systematic review, Zaveri et al. compared abdominal cervico-isthmic cerclage and classic vaginal cerclage (McDonald or Shirodkar techniques) after a failed McDonald cerclage (17). They showed that transabdominal cervico-isthmic cerclage was associated with a lower risk of perinatal death or delivery at $<24$ weeks of gestation, but with a higher rate of serious operative complications. In addition, abdominal cervico-isthmic cerclage led to two conversions to laparotomy. The vaginal approach reduced these operative complications (20). 
One study compared vaginal cervico-isthmic and abdominal cervico-isthmic cerclage (21) and found no difference between the groups with regard to perinatal survival rates.

However, vaginal cervico-isthmic cerclage has never been described for emergency cerclage. The operative technique used was similar with the one used for planned cervico isthmic cerclage.

There is no consensus on the definition of emergency cerclage. Some authors consider emergency cerclage only if there are prolapsed membranes at or beyond the external os, while others consider emergency cerclage as necessary if the cervical length is less than $25 \mathrm{~mm}$ at transvaginal sonography. It can lead to significant differences in evaluation of emergency cerclage. In the presented study, the women all had prolapsed membranes.

Whatever the definition, the efficiency and safety of emergency cerclage is still controversial because there is only one randomised study: by Althuisius et al. (5). In this study, they combined emergency cerclage with indomethacin administration and, as a result, appeared to reduce the rate of preterm delivery compared to bed rest alone.

A literature review of 34 studies in which transvaginal emergency cerclage was performed also showed good efficiency with a longer latency period and better neonatal outcomes compared to expectant management. Predictors of poor outcome were prolapsed membranes, evidence of intra-amniotic or systemic infection, symptomatic presentation, cervical dilatation greater than $3 \mathrm{~cm}$, or cerclage after 22 weeks (22).

In another prospective study that compared emergency cerclage and bed rest treatment (23), a longer mean gestational age at delivery, fewer preterm membrane ruptures, and higher mean birth weight were found in the emergency cerclage group .

Daskalakis et al. included 46 women who presented cervical dilatation and prolapsed membranes. Twenty-nine women received McDonald emergency cerclage and 17 women refused cerclage and composed the bed rest group. They showed that pregnancy was 
significantly prolonged in the emergency cerclage group ( 8.8 weeks versus $3.1(p<0,001))$. The preterm delivery before 32 weeks rate was also significantly lower in the cerclage group (24).

The originality of this study is that it is the first to report cases of definitive emergency transvaginal cervico-isthmic cerclage using a polypropylene sling. In most of the studies, McDonald cerclages are performed. In one published study, the author reported results of an emergency modified Shirodkar cerclage. The procedure was performed in five women. Two women delivered after 36 weeks of gestation (36 and 39 weeks). Three women experienced severe chorioamnionitis following the surgical procedure and delivered before 25 weeks of gestation (25).

Joung et al. also reported 2 successful cases of emergency abdominal cervico-isthmic cerclage without complications (26). In the first case, they performed a laparotomic cervicoisthmic cerclage at 21 weeks of pregnancy after a failed Shirodkar cerclage. The cervical length was $7 \mathrm{~mm}$ at the time of the cervico-isthmic cerclage. The woman delivered at 38 weeks. In the second case, they also performed an emergency abdominal cervico-isthmic cerclage at 18 weeks of pregnancy because of a short cervix measured at $18 \mathrm{~mm}$ with a previous abortion and an antecedent of conisation. The woman in this case finally delivered at 38 weeks. There were no complications during the two procedures, but in both cases, the cervix was short without visualisation of membranes at the external os.

A laparoscopy during pregnancy is, however, always difficult and presents risks, as it can induce contractions and preterm delivery. Contraindication of uterine cannulation and the size of the uterus considerably reduce exposure and make the procedure very difficult (27). Moreover, the risk of bleeding is significant due to the proximity of the broad ligament and of the parametrial veins. The risks of laparoconversion are also important. In such a case of emergency cerclage, the vaginal route is probably easier. 


\section{CONCLUSION}

Despite the small number of women included, this study shows that transvaginal emergency cervico-isthmic cerclage can be performed with interesting results. This technique requires careful selection of women after failure of McDonald cerclage and a trained surgeon.

Cases of successful or unsuccessful emergency cervico-isthmic cerclage have to be reported in order to obtain a larger series and to evaluate the safety of this surgery. 


\section{REFERENCES}

1. EPOPé I. Enquête nationale périnatale Rapport 2016. http://www.epopéinserm.fr/grandes-enquetes/enquetes-nationales-perinatales.

2. Martin JA, Hamilton BE, Osterman MJ, Driscoll AK, Drake P, Statistics D of V. National Vital Statistics Reports Births : Final Data for 2016. Natl Vital Stat Reports. 2018;67(1).

3. Marcellin L. Prevention of preterm birth by uterine cervical cerclage. J Gynecol Obstet Biol la Reprod. 2016;45(10):1299-323.

4. Capmas P, Thellier E, Carcopino X, Huchon C, Deffieux X, Fernandez H. Prise en charge d' un antécédent de fausse couche tardive ( 14 à 22 SA ) Management of women with a previous late fetal loss ( 14 to 22 SA). J Gynecol Obstet Biol la Reprod. $2014 ; 43(10): 856-64$.

5. Althuisius SM, Dekker GA, Hummel P, Van Geijn H. Cervical incompetence prevention randomized cerclage trial : Emergency cerclage with bed rest versus bed rest alone. Am J Obs Gynecol. 2003;189:907-10.

6. Benifla J-L, Goffinet F, Darai E, Proust A, De Crepy A, Madelenat P. Emergency cervical cerclage after 20 weeks' gestation: a retrospective study of 6 years' practice in 34 cases. Fetal Diagn Ther. 1997;12:274-8.

7. Stupin J, David M, Siedentopf J, Dudenhausen J. Emergency cerclage versus bed rest for amniotic sac prolapse before 27 gestational weeks A retrospective, comparative study of 161 women. Eur J Obstet Gynecol. 2008;139:32-7.

8. Wang S, Feng L. A single-center retrospective study of pregnancy outcomes after emergency cerclage for cervical insufficiency. Int J Gynaecol Obs. 2017;139:9-13.

9. Steenhaut $P$, Hubinont $C$, Bernard $P$, Debiève F. Retrospective comparison of perinatal outcomes following emergency cervical cerclage with or without prolapsed membranes. Int J Gynaecol Obs. 2017;137:260-4.

10. Shirodkar J. A new method for operative treatment for habituals abortions in the second trimester of pregnancy. Antiseptic. 1955;52:299-300.

11. McDonald I. Suture of the cervix for inevitable miscarriage. J Obs gynecol Br Emp. 1955;64:346-50. 
12. Benson RC, Durfee RB. Transabdominal cervico uterine cerclage during pregnancy for the treatment of cervical incompetency. Obs Gynecol. 1965;25:145-55.

13. Lesser K, Childers J, Surwit E. Transabdominal cerclage: a laparoscopic approach. Obs Gynecol. 1998;91:855-6.

14. Scibetta J, Sanko S, Phipps W. Laparoscopic transabdominal cervicoisthmic cerclage. fertil Steril. 1998;69:161-3.

15. Deffieux X, De Tayrac R, Louafi N, Gervaise A, Sénat MV, Chauveaud-Lambling A, et al. Transvaginal cervico ithmic cerclage using polypropylene tape: surgical procedure and pregnancy outcome: Fernandez's procedure. J Gynecol Obs Biol Reprod. 2006;35:465-71.

16. Davis G, Berghella V, Talucci M, Wapner RJ. Patients with a prior failed transvaginal cerclage: A comparison of obstetric outcomes with either transabdominal or transvaginal cerclage. Am J Obs Gynecol. 1999;183:836-9.

17. Zaveri V, Aghajafari $F$, Amankwah K. Abdominal versus vaginal cerclage after a failed transvaginal cerclage : A systematic review. Am J Obs Gynecol. 2002;187:868-72.

18. Neveu ME, Fernandez H, Deffieux X, Senat M, Houllier M, Capmas P. Fertility and pregnancy outcomes after transvaginal cervico-isthmic cerclage. Eur J Obstet Gynecol. 2017;218:21-6.

19. Capmas P, Letendre I, Leray C, Deffieux X, Duminil L, Subtil D, et al. Vaginal cervicoisthmic cerclage versus McDonald cerclage in women with a previous failure of prophylactic cerclage: A retrospective study. Eur J Obstet Gynecol Reprod Biol. 2017;216:27-32.

20. Golfier F, Bessai K, Paparel P, Cassignol A, Vaudoyer F, Raudrant D. Transvaginal cervicoisthmic cerclage as an alternative to the transabdominal technique Franc. Eur $\mathrm{J}$ Obstet Gynecol. 2001;100:16-21.

21. Witt M, Joy S, Clark J, Herring A, Bowes W, Thorp J. Cervicoisthmic Cerclage: Transabdominal Versus Transvaginal Approach. Am J Obs Gynecol. 2009;201(1):1-9.

22. Namouz S, Porat S, Okun N, Windrim R, Farine D. Emergency cerclage: literature review. Obs Gynecol Surv. 2013;68(5):379-88.

23. Olatunbosun O, Al-Nuaim L, Turnell R. Emergency cerclage compared with bed rest for 
advanced cervical dilatation in pregnancy. int Surg. 1995;170-4.

24. Daskalakis G, Papantoniou N, Mesogitis S, Antsaklis A. Management of Cervical Insufficiency and Bulging Fetal Membranes. Obs Gynecol. 2006;107(2):221-6.

25. Masaki O, Hironyuki S, Tsuda A, Hirano H, Tanaka T. Modified cervical cerclage in pregnant women with advanced bulging membranes: knee-chest positioning. Acta Obstet Gynecol Scand. 1999;78(2):779-82.

26. Joung E, Go E, Kwack JY, Kwon YS. Successful term delivery cases of trans-abdominal cervicoisthmic cerclage performed at more than 18 weeks of gestation. Obs Gynecol Sci. 2016;59(4):319-22.

27. Gallot D, Savary D, Laurichesse H, Bournazeau J, Amblard J, Lémery D. Experience with three cases of laparoscopic transabdominal cervico-isthmic cerclage and two subsequent pregnancies. BJOG. 2003;110:696- 700. 